\title{
Patient-Oriented Research from the ISDM 2019 Conference: A Legacy Now More Relevant Than Ever
}

\author{
Patrick M. Archambault ${ }^{1,2,3,4}$. S Sabrina Guay-Bélanger ${ }^{2,5,6}$. Véronique Gélinas ${ }^{2,3,4}$ - Anik Giguère ${ }^{1,2,5}$. \\ Claire Ludwig $^{7} \cdot$ Mame Awa Ndiaye $^{8} \cdot$ Kathy Kastner $^{9} \cdot$ Dawn Stacey $^{10,11} \cdot$ Nick Bansback $^{12} \cdot$ Gary Groot $^{13}$. \\ France Légaré ${ }^{1,2,5,6}$
}

Accepted: 19 September 2020 / Published online: 16 October 2020

(c) Springer Nature Switzerland AG 2020

In July 2019, Canada hosted the 10th International Shared Decision Making (ISDM) conference in Quebec City on campus at Université Laval. This biannual conference brought together 429 delegates from 22 countries to share their work about patient-oriented shared decision making (SDM) research. Patient-oriented research refers to a continuum of research that engages patients as partners, focusses on patient-identified priorities and improves patient outcomes [1]. SDM involves health professionals and patients making decisions together based on the best available evidence, health professionals' experience and patients' values and preferences [2]. Patient-oriented research is thus an optimal framework to conduct research about SDM. Multiple milestones occurred during the ISDM 2019 conference, including (i) it was the first ever Patients Included ISDM conference; (ii) it was led by a consortium of scientists representing four universities (Université Laval, University of Ottawa, University of Saskatchewan and University of British Columbia) and co-chaired by patient partners; (iii) its central office was supported by staff at the Canada Research Chair in Shared Decision Making and Knowledge

Patrick M. Archambault

patrick.m.archambault@gmail.ca;

patrick.archambault@fmed.ulaval.ca

1 Department of Family and Emergency Medicine, Université Laval, Québec, QC, Canada

2 VITAM-Centre de recherche en santé durable, Québec, QC, Canada

3 Centre intégré de santé et de services sociaux de Chaudière-Appalaches, Ste-Marie, QC, Canada

4 Centre de recherche intégrée pour un système apprenant en santé et services Sociaux, Centre intégré de santé et de services sociaux de Chaudière-Appalaches, Lévis, QC, Canada

5 Centre intégré Universitaire de santé et de Services Sociaux de la Capitale-Nationale (CIUSSS-CN), Québec, QC, Canada
Translation [3]; (iv) it was the official launch of the ISDM Society [4] and (v) it was the first time that a special issue of The Patient-Patient Centered Outcomes Research journal reported on notable research presented during this conference. As well, the five leaders who initiated this research community were reunited and honoured at the 2019 conference: Angela Coulter, Annette O'Connor, Hilary LlewellynThomas, Margaret Holmes-Rovner and David Rovner. During three science-packed days, new knowledge was shared, new relationships were created, lasting relationships were reinforced, and inspiring presentations were given by a mix of diverse stakeholders such as patient partners, researchers and decision makers.

All in the name of science and the spirit of patient-oriented research, this conference brought together people, citizens and leaders in SDM to share a common vision about how science could be produced and disseminated differently with significant guidance from patient partners. There were 10 pre-conference workshops, 12 meetings of special interest groups, 178 oral presentations and 202 poster presentations. This conference energized many of its attendees to pursue

6 Canada Research Chair in Shared Decision Making and Knowledge Translation, Université Laval, Québec, QC, Canada

7 Patient Partner, Ottawa, ON, Canada

8 Patient Partner, Québec, QC, Canada

9 Patient Partner, Toronto, ON, Canada

10 Faculty of Health Sciences, School of Nursing, University of Ottawa, Ottawa, ON, Canada

11 Ottawa Hospital Research Institute, Ottawa, ON, Canada

12 School of Population and Public Health, University of British Columbia, Vancouver, BC, Canada

13 Department of Community Health and Epidemiology, University of Saskatchewan, Saskatoon, SK, Canada 
their ongoing patient-oriented SDM research and to plan future research where patients would have greater voices in producing new knowledge, planning implementation of study findings, and partnering in decisions for more usable research findings, nothing less! The ISDM Conference will reconvene again in June 2021 in Denmark to continue this work. However, since the last meeting, a major event occured that changed our lives and the course of history.

Countries around the world have now been struggling for months to cope with the COVID-19 pandemic, one of the largest and most deadly public health emergencies in the last century [5]. As of September 2020, the worldwide toll now stands at more than 25 million individuals infected and more than 850,000 deaths [6], notwithstanding the suffering of millions more and the enormous economic strife that will affect society for months, if not years to come. The world has also lost many of its seniors, the voice of guidance and wisdom in many societies [7].

Despite the uncertainty that hangs over us with a potential second wave, the scientific community must rise and unite to fight this pandemic. We must draw on the energy and spirit of our lost seniors to continue working towards more just and equitable healthcare around the world. We surmise that we must return back to July 2019, where we left off, to remember the principles of patient-oriented research [8]. Even though the pandemic has been a challenge for patientoriented research, it has made it ever so more relevant than before.

In the last months, the importance of high-quality science and of 'real news' (to counterbalance 'fake news') has come to the forefront as an essential service for society. The dissemination of high-quality evidence has become a headline for media outlets around the world. Unfortunately, poorquality evidence and ill-advised opinion has sometimes led some policy makers down dangerous routes. This should remind us of the importance of patient-oriented research and its benefits for producing high-quality evidence that is relevant to citizens, clinicians and decision makers alike.

The pandemic also brought to the forefront the importance of using SDM principles broadly in health care services. With limited yet rapidly emerging evidence during the COVID-19 pandemic, patients and citizens around the world are faced with many emerging difficult health and social decisions, feeling confused and overwhelmed when faced with choosing an option. Should I go on a mechanical ventilator? Should I temporarily move my loved one from their retirement home to our family home? Should I delay my chemotherapy treatment? Should I send my child back to school? Should I get this new symptom investigated? Scientists, patients and policy makers have united to offer decision-making tools to support patients in making these difficult and ethically challenging decisions during COVID-19 [9-11]. However, there remains an urgent need to continue this work and produce more high-quality evidence and more effective decision aids to engage patients in achieving quality SDM. Now more than ever, citizens and patients around the world need effective decision support for making informed, value congruent health and social decisions that will translate into better outcomes [12]. In other words, this pandemic has increased patients' needs to be empowered and ensure that their values prevail during this challenging time.

The ISDM conference in July 2019 was leading us towards this virtuous patient empowerment goal. At this Patients Included conference, patients co-led the conference planning committees, a patient provided one of the keynote presentations, 41 patient partners attended, and patients comoderated the oral presentations with a researcher. Patients presented inspirational and memorable presentations about living with their illnesses and innovative work to foster more patient engagement in research [13], and contributed to the discussion [14]. Twenty-three bursaries were awarded to patient partners to support their attendance. Funding was provided to support their participation by different organizations including Québec's Strategy for Patient-Oriented Research Support Unit (Unité de soutien SRAP du Québec) and other different healthcare organizations [15] as well as multiple partner organizations and private enterprises.

After the conference, an editorial committee convened with The Patient-Patient Centered Outcomes Research to create a special edition of the journal to continue disseminating the work presented at ISDM 2019. This edition highlights the research produced in partnership with patients and presented at ISDM 2019. In response to the call for papers, 39 manuscripts were submitted from around the world with 23 from the Americas, 9 from Europe and 7 from Asia. In line with the conference theme, a major criteria for selecting manuscripts for this special edition was that a patient partner had to be an author or co-author of the work. As well, the included papers were selected after a thorough peer review process that included patients as some of the peer reviewers.

It has been our privilege to chair the ISDM 2019 conference and resulting special edition. After having organized this conference, selected and peer-reviewed the papers presented in this special issue and adapted our timeline to the ever-changing priorities of COVID-19, we would like to highlight some of the positive outcomes we believe emerged from this unique experience.

First, patients had and will continue to have an active voice in guiding future research in SDM. In this issue of The Patient-Patient Centered Outcomes Research, you will find selected papers that represent a sample of the benefits of such patient-oriented research in the production of decision aids to support patient engagement in clinical trials [16], to empower patients with complex care needs in guiding their case management [17], to undergo a computerized head tomography for mild traumatic brain injury 
[18] and to guide pain management [19]. You will also discover best-worst scaling methods to engage patients in identifying surgical complications they want to be informed about [20] and use of social media to determine what is important for citizens during end-of-life discussions [21].

Second, this was one of the first international conferences where patients played such an important role in creating and translating knowledge. Conferences play an important part in creating knowledge and inspiring new research questions. Having patients participate in this important part of research was a highlight from this conference. Conducting future conferences with this Patients Included approach will help transform how research is conducted and help break down certain ethical barriers to accelerate the production of patient-oriented research [21].

Third, some countries have advanced patient-oriented research more than others and we have seen this reflected in the submissions to the journal. It is noted that we had more submissions that met our selection criteria from Canada and the United States as well as other industrialized countries. Low and middle income countries (LMICs) were less well represented in our final list of selected manuscripts. This perhaps highlights that geographical representation within this special edition was potentially determined by the location of the conference (i.e. cost of travel), which may have skewed the results towards North America. It could also point to the need for better support for researchers and patients from LMICs.

More work needs to be done to better include patients and foster meaningful involvement in research. In particular, patient-oriented SDM research would benefit from better including the voices of low-income patients from around the world. The current pandemic has also raised many issues about how to involve patients in the context of a pandemic, as the next ISDM in 2021 may be held using a web-based format. The involvement of older adults, who are at the forefront of several of the COVID-related research initiatives, is even more challenging given their higher vulnerability to the virus. It has also raised the importance of long-lasting collaborations and relationships, because building new ones can be difficult in times of social distancing. Relationships that can be created through in-person conferences, like the ISDM 2019, are more likely to lead to meaningful research collaborations between patients and scientists.

The ISDM 2019 conference was remarkable and its model should be replicated to continue supporting future patient-oriented research. The current global pandemic has somewhat threatened and raised the profile of patient-oriented research to a new level. The need for better patient and clinician engagement in SDM and SDM research is essential in these times of uncertainty.
Acknowledgements The authors especially thank the patients who attended the meeting, and all the organizing, scientific and international committee members.

\section{Compliance with ethical standards}

Funding The 10th ISDM Conference was supported by contributions from Bertelsmann Stiftung, Diabetes Action Canada, VITAM - Centre de recherche en santé durable, Fédération des médecins omnipraticiens du Québec, EBSCO Health, Fonds de recherche du Québec - Santé, Québec SPOR Support Unit, Collège québécois des médecins de famille, Centre de recherche du CHU de Québec - Université Laval, Robert Bosch Stiftung, The College of Family Physicians of Canada, CISSS de Chaudière-Appalaches, and Quebec City Tourism, and an in-kind contribution from the Tier 1 Canada Research Chair in Shared Decision Making and Knowledge Translation and the ISDM Society.

Conflict of interest None to declare.

Ethics approval Not applicable as this is an editorial and no results are presented.

Consent to participate Not applicable.

Consent for publication All authors have consented to publish.

Availability of data and materials Not applicable.

Code availability Not applicable.

Author contributions PMA wrote the first draft of the manuscript. All authors read, provided feedback on, and approved the final manuscript.

\section{References}

1. Government of Canada, Canadian Institutes of Health Research, Research, Translation K. Strategy for patient-oriented researchpatient engagement framework [Internet]. 2014 [cited 2020 Sep 4]. Available from: https://cihr-irsc.gc.ca/e/48413.html.

2. Elwyn G, Edwards A, Kinnersley P, Grol R. Shared decision making and the concept of equipoise: the competences of involving patients in healthcare choices. Br J Gen Pract. 2000;50(460):892-9.

3. Canada Research Chair in Shared Decision Making and Knowledge Translation [Internet]. [cited $2020 \mathrm{Sep} 1]$. https://www.decis ion.chaire.fmed.ulaval.ca/accueil-en.

4. ISDM Society [Internet]. [cited 2020 Sep 1]. https://www.isdms ociety.org/.

5. Petersen E, Koopmans M, Go U, Hamer DH, Petrosillo N, Castelli $\mathrm{F}$, et al. Comparing SARS-CoV-2 with SARS-CoV and influenza pandemics. Lancet Infect Dis. 2020;20(9):e238-e244244.

6. COVID-19 Map-Johns Hopkins Coronavirus Resource Center [Internet]. [cited 2020 Sep 1]. https://coronavirus.jhu.edu/map. html.

7. Hampton M, Baydala A, Bourassa C, McKay-McNabb K, Placsko $\mathrm{C}$, Goodwill $\mathrm{K}$, et al. Completing the circle: elders speak about end-of-life care with aboriginal families in Canada. J Palliat Care [Internet]. 2010 [cited 2020 Jul 8];26(1). https://pubmed.ncbi.nlm. nih.gov/20402179/.

8. Archambault PM, McGavin C, Dainty KN, McLeod SL, Vaillancourt C, Lee JS, et al. Recommendations for patient engagement 
in patient-oriented emergency medicine research. CJEM. 2018;20(3):435-42.

9. Ottawa Hospital Research Institute-Patient Decision Aids [Internet]. [cited 2020 Jul 9]. https://decisionaid.ohri.ca/decaids.html.

10. Advance Care Planning in Primary Care. [cited 2020 Jul 9]. https ://primarycareacp.org/materials.

11. Totten AM, Fagnan LJ, Dorr D, Michaels LC, Izumi SS, Combe A, et al. Protocol for a cluster randomized trial comparing teambased to clinician-focused implementation of advance care planning in primary care. J Palliat Med. 2019;22(S1):82-9.

12. Stacey D, Légaré F, Lewis K, Barry MJ, Bennett CL, Eden KB, et al. Decision aids for people facing health treatment or screening decisions. Cochrane Database Syst Rev. 2017;4:CD001431.

13. Claire Ludwig @ the International Shared Decision Making Conference [Internet]. [cited 2020 Sep 1]. https://health.uottawa.ca/ nursing/news/claire-ludwig-international-shared-decision-makin g-conference.

14. Burch T. Patient commentary: added value and validity to research outcomes through thoughtful multifaceted patient-oriented research. Patient [Internet]. 2020. http://doi.org/10.1007/ s40271-020-00432-9.

15. ISDM 2019-10e conférence internationale sur la décision partagée [Internet]. [cited $2020 \mathrm{Jul} 9$ ]. https://www.fourwav.es/ view/935/customtab437/.
16. Parry M, et al. Patient engagement partnerships in clinical trials: development of patient partner and investigator decision aids. Patient. 2020. https://doi.org/10.1007/s40271-020-00460-5 (in press)

17. Poitras, M-E, et al. High users of healthcare services: development and alpha-testing of a patient decision aid for case management. Patient. 2020 (in press)

18. Ghandour EK, et al. Adapting two American decision aids for mild traumatic brain injury to the Canadian context using the nominal group technique. Patient. 2020 (in press)

19. April KT, et al. Development and acceptability of a patient decision aid for pain management in juvenile idiopathic arthritis: the JIA option map. Patient. 2020. https://doi.org/10.1007/s4027 1-020-00458-Z

20. de Mik SML, Rietveld B, Auwerda A, et al. Best-worst scaling study to identify complications patients want to be informed about prior to abdominal aortic aneurysm surgery. Patient. 2020. https ://doi.org/10.1007/s40271-020-00438-3.

21. Kastner K. Eliciting what matters most to people: the whiteboard initiative proof of concept. Patient. 2020. https://doi.org/10.1007/ s40271-020-00435-6. 